\title{
Development of Tailored Early Warning Agromet Advisories for Farmers in Zambia, Indonesia, and South Africa
}

\author{
Sue Walker ${ }^{1,2 *}$ \\ ${ }^{1}$ Agricultural Research Council-Natural Resources and Engineering, Pretoria, South Africa, ${ }^{2}$ Department of Soil, Crop, and \\ Climate Sciences, University of the Free State, Bloemfontein, South Africa
}

\section{OPEN ACCESS}

Edited by:

Tamuka Magadzire,

University of California, Santa Barbara,

United States

Reviewed by:

Peter Johnston,

University of Cape Town, South Africa

Bridget Bwalya Umar,

University of Zambia, Zambia

Robert Stefanski,

World Meteorological

Organization, Switzerland

*Correspondence:

Sue Walker

WalkerS@arc.agric.za

Specialty section:

This article was submitted to

Climate Services,

a section of the journal

Frontiers in Climate

Received: 16 May 2021

Accepted: 27 August 2021 Published: 17 September 2021

Citation:

Walker S (2021) Development of Tailored Early Warning Agromet Advisories for Farmers in Zambia, Indonesia, and South Africa.

Front. Clim. 3:710625.

doi: 10.3389/fclim.2021.710625
Farmers do not often use climate and weather information on a regular basis, as the specific influence of weather parameters on farm-level decision making is not well-known. Agromet advisories are needed for local farming systems. Effective agrometeorological advisory systems, need tailored agricultural weather forecasts, and two-way communication. Transdisciplinary teams together with farmers can co-develop early warning Agromet advisory systems to address farmers' needs. Three examples of Agromet advisories are discussed- CAPES in Zambia, Science Field Shops in Indonesia, and the AgriCloud mobile App in South Africa. Community Agrometeorological Participatory Extension Service (CAPES) began in Monze, Zambia to communicate seasonal climate forecasts to farmers through researchers and extension interactions. Participatory groups collected spatial and temporal data about local farming systems to highlight opportunities. Communication methods used were local radio, farmers' days, trials, with farm visits. CAPES resulted in lifelong learning about climate and co-development of tailored Agromet advisories to improve climate resilience. In Science Field Shops (SFS) groups of Indonesian farmers meet experts regularly to exchange information about climate and farming activities. Farmers measure rainfall and observe their agroecological systems each day. At monthly meetings, the seasonal forecasts are discussed using dialogue-discussion methods. Agrometeorological learning is trans-disciplinary through interaction between anthropologists, agrometeorologist, and extension personnel. SFS includes eight climate services that empower farmers to address challenges and sustain their productivity. AgriCloud is an online weather-based agricultural advisory system enriching weather forecasts with agricultural information and local knowledge. Real-time overviews and warnings are tailored to farmer's needs. AgriCloud provides farmers, extension staff, and advisors daily updated weather-related farm-specific advice in 11 South African official languages. AgriCloud is available as an android mobile App, or API to use via a platform. These examples illustrate the use of weather forecasting together with tailored forecasts and communication systems to deliver Agromet advisories, showing different aspects of the incorporation of local knowledge in co-developing advisories for the farmers. In the future, various combinations can be used around the world when co-developing with the farmers. 


\section{INTRODUCTION}

Effective practical local early warning agromet advisories can be developed using participatory approaches in order to incorporate local knowledge to farmers on a routine basis. This local and indigenous knowledge is then used to refine the agricultural scientific information for the local conditions and provide information to farmers such as planting dates and suitable crop selections according to the current and expected weather conditions. Although farmers know about the general effects of weather and climate on their agricultural production, it is more difficult for them to extrapolate pertinent information relevant to their activities directly from a standard weather forecast (Stigter et al., 2013). Therefore, it is important that agrometeorologists use the available scientific evidence from research results to generate operational level agromet advisories. An agromet advisory is a message combining weather or climate information with specific information about the farming systems in the form of advice on farming activities. In South Africa, despite the existence of good historic climate datasets (ARC-Agromet database 2021) and good daily weather forecasts (www.weather.co.za) farmers do not often combine this information to use in their decision making. Many are not even aware of the detailed cumulative effects of the current and seasonal weather forecast on their agricultural enterprises. Therefore, it is important to formulate and operationalize routine Agromet advisories for each farming system and location including a range of options and management skills.

For an effective agrometeorological advisory system, aspects needed include

- scientific weather forecasting numerical models,

- monitoring systems,

- added agricultural value for tailored forecasts, and

- a good two-way communication system to deliver messages and receive feedback.

Some developed countries have been using especially tailored agromet advisories that were co-developed with the farming community for many years. Examples of such agromet services are in Australia under the FARMSCAPE approach to decision support where farmers, advisers, and researchers were involved in monitoring, simulation, communication and performance evaluation together (Carberry et al., 2002). The programme that developed and operated for over a decade, integrated farmer participation with the results particularly from the APSIM farming systems model to provide a scientific approach to decision support specifically using farmers information about their farming operations. Another example is in Florida, USA where a framework was developed with many activities integrated yet running parallel, including physical, biological, social, and economic aspects of agricultural systems (Jagtap et al., 2002). The framework included the generation of climate information from historic datasets and models, the communication though interactions with stakeholders, to the use, implementation and evaluation of the system which designed and developed agromet early warning advisories to assist the citrus farmers in receiving information about potential low temperatures that would adversely affect their trees. These are well-established, scientifically based and validated early warning services to specific parts of the agricultural sector (Walker and Stigter, 2010). These two examples, illustrate how the conventional weather forecast needs to be enhanced with additional information relevant to the farming operations in the area. However, in other countries such agromet advisory services are not operational on a routine basis.

Many times the direct and indirect influence of the weather on agricultural activities on a farm level and hence the decisionmaking processes of farmers for specific farming systems, are not well-defined and can include indigenous knowledge (ZumaNetshiukhwi et al., 2013). Therefore, these aspects need to be part of co-investigation participatory projects, as farmers are not able to use the highly technical scientific information provided by the national meteorological and hydrological services (NMHS) in their day to day decisions or seasonal planning (Elhag and Walker, 2011). Typical conventional weather forecast only give expected values for weather parameters such as temperature and/or humidity and are often not related to the long-term means or variability experienced in past to put them in perspective. Agromet advisory services need to be co-developed together with the users, the farmers, farm managers and extension workers to formulate viable solutions (Walker et al., 2010). Transdisciplinary teams should co- develop effective integrated systems to interpret weather forecasts in relation to farming management decisions and then to develop systems to routinely deliver them to the farming community at the correct time. Such teams working together with the farmers can co-develop and design early warning and Agromet advisory systems to address the farmers' specific needs and questions according to their location and production systems (Stigter et al., 2014a,b,c). Three examples of development of such Agromet advisories are discussed, namely the CAPES in Zambia, the Science Field Shops in Indonesia, and the AgriCloud mobile App in South Africa. Important aspects needed during development of these advisory services are highlighted.

\section{COMMUNITY AGROMETEOROLOGICAL PARTICIPATORY EXTENSION SERVICE}

Community Agrometeorological Participatory Extension Services (CAPES) were established in some Mujika villages near Monze, Zambia to introduce and communicate seasonal climate forecast to farmers through interactions between the farmers, researchers and extension practitioners. This method was developed during Dr. Durton Nanja's Ph.D. study from 2007 to 2010 as he engaged the community and developed the methods to distribute the season forecast to the farmers in Mujika near Monze (Nanja, 2010). The process began with an interaction with the extension staff of the Zambia Department of Agriculture, the headmen of the villages to establish a good working relationship in order to obtain permissions to use the various participatory approaches to collect information from the farmers about the currently used farming systems and the natural resources. These interactions were typical focus group 
meetings, similar to those used by Nyumba et al. (2018) to inform leaders in the community about the development of the agromet services and to arrange the community communications and interactions. During these meetings, participatory methods were used to identify the limiting factors in the local current farming systems (Nanja and Walker, 2009).

Prior to the community meetings, background information about the area for which the agromet services were being designed was obtained from secondary sources. Much of this information was obtained by a desktop study of the available natural resources and the current farming systems, being collected from the appropriate government departments archives and databases. However, as in many cases, the details needed were at a rather large scale without sufficient detail at the local scale of the actual farms. So the general topographic information about the contours or lie of the land and location of the rivers was obtained from topographic maps. The detailed soils information was not available at the time of the study that started in 2007, but is now accessible from the Soil Atlas of Africa (Jones et al., 2013) namely Chromic Luvisols (with clay subsoil), undifferentiated Acrisols (acid with clay rich subsoil) and Lithic Leptosols (shallow soils over rock) around Monze. The long-term climate information was obtained for two climate stations namely Magoye weather station and Moorings rainfall observing station from the Zambia Meteorological Department (ZMD) Provincial Meteorological Office with 29 and 86 years climate and rainfall records, respectively. These long-term data can be used together with the more recent reanalysis data available from NASA (POWER, https://power.larc.nasa.gov/) at a spatial resolution of $0.5^{\circ}$ latitude by $0.5^{\circ}$ longitude across the globe available from 1981. The other natural resources data was collected from the appropriate departments such as agriculture, water and environment. This information provided a background to the area and was supplemented with general information about the farming systems and the markets in the area. However, as the Agromet services are to serve the farmers themselves, one also needed to engage and interact with them and gather information directly from such farmers.

Participatory group activities include the collection of spatial and temporal data about the local farming systems and climatic conditions from the communities perspective. One of the best ways of doing this is using participatory techniques (Chambers, 2006, 2007). Such methods enable the farmers to also learn during the process, so that there can be joint ownership of the information together with empowerment, or enabling people to have what they need to solve their own problems. It was important to communicate the aims of such activities so that each group understood the reasons behind such activities. That helped to maintain focus during the sessions and later when prioritizing the information. The criteria were co-developed within some ground rules used during these activities.

Participatory techniques were used in a group context in each of the villages to enable them "to learn by doing" as they explore their own local resources. The techniques integrated community and farm mapping and transect walks (IFAD, 2009) to document the information about the lie of the land from stream or river through the flood plain to the cultivated fields and on toward the village and hills. Along the way during each transect walk in the three selected villages, each person took notice of the changes in vegetation and soils, which were then included in or provided complementary information to the specific map of that village. These community mapping exercises helped the villagers to articulate and express their spatial knowledge that was recorded by the researchers and archived local knowledge to assists in the crop modeling, land-use planning and resource management. These transect walks through the village and farmlands was a form of capacity building, as the people could explore the spatial dimension and integrate social aspects (e.g., taxi ranks and marketing opportunities) into the natural resources information. It is used to cross check with the other mapping activities and help the researchers with triangulation or confirmation of certain aspects. As a village group, they then drew a map and a transect on a large sheet of paper to represent the variety of aspects observed. Contributions from everyone were easily collated and added to the map that was then used later as a basis for planning interventions or services.

During the group discussion, the facilitator was able to highlight the issues discussed and how the climate and weather might affect each of them (Gandure et al., 2013). This opened the door for further discussion later about agromet services that were to be developed to address these locally pertinent questions. The participatory mapping exercises were integrated with the information from the desktop study to provide a base for further investigations. These included the siting of future developments, or location of a market or expansion of the agricultural activities.

Other participatory techniques used include the time lines at various scales. Timelines are a visualization tool build up by group contributions to show a list of sequential events that reflects their common history or activities. They helped to give context to the present conditions and situation so that the villagers could reflect on the trends and development and think strategically about a plan for the future. During the group discussions, the facilitator drew a time line of a flip chart and then filled it in as the farmers responded with suggestions. For the long-term time scale (years) information was collected about different aspects of past droughts and floods as well as highlighting historic milestones and other significant developments in the area. In the seasonal shorter-term (weeks or months) farmers gave details of their farming systems and typical operations like timing of land preparation (plowing), planting, weeding, fertilizer top-dressing and harvest time. All the results from these participatory activities helped the researchers to better understand cropping operations from the farmers point of view, and gave opportunity to highlight the critical times during the growing season. This information was later used in the crop modeling exercise. The daily time lines illustrated the difference between male and female daily routines and responsibilities of the typical complex life in the area. All this information was then used when planning and developing the agromet services, tailored and relevant to the specific seasonal activities in their local farming system and their daily routines. For example, the seasonal calendar represented the activities for the specific dryland maize cropping with integrated cattle livestock system and showed how the spread of their workload through the year 
was related to the local climate (similar to Hall et al., 2017). Once the timelines were drawn by the farmers, then the critical periods were able to be identified together with the trigger weather parameters, such as the start of the rains. This then formed the basis of the agromet advisory that was be developed and distributed to the farmers on a routine basis. For example, they highlighted that they cannot begin plowing for land preparation and planting before they have received some rainfall, as the soil surface is too hard for the animal traction plow to break up the soil. This information, was then used to develop an algorithm based on the daily weather forecasts for a certain planting season, so as to formulate the added value agromet advisories.

Once the all the information was collected from the Mujika villages group interactions it was collated, highlighting the most important aspects identified by the farmers and other participants (like agricultural camp officers). It was then used to formulate responses to address problems and opportunities ranked by farmers using matrices as a preference ranking exercise according to their own cultural priorities (similar to Ager et al., 2010). Here the ranking method was used, where firstly the group brainstormed a list of the priority issues or problem areas that they wanted to see addressed. This formed a slightly different matrix for each group of participants, they then voted for the top three or four priority areas that they considered as priorities needing attention. Following the counting of the votes, there was further discussion to bring consensus about the highest priority issues. An ensuing analysis was then conducted to unpack the extent of each problem, the impacts on their farming systems and other associated effects. During this process the opportunities to address such issues was discussed with additional scientific perspective from the currently available information by the researcher and camp officer and how they could be packaged to form an agromet advisory for these specific villages.

In Mujika for CAPES, community engagement continued via the development of a community dissemination plan that was formulated by the farmers and extension staff, in order to develop and maintain a routine agromet services. This community information dissemination plan was designed specifically by these villages at this time, so it selected the appropriate communication methods that could be used in Monze district. The following methods to disseminate the agromet advisories were initiated-weekly local radio programmes that were listened to by farmer study "radio listening" groups; regular farmers' days to visit the "on-farm mother-baby" trials (see later) to investigate a variety of aspects of the farming systems (similar to methods used by Eldon et al., 2020; Périnelle et al., 2021); together with training activities; farm, field and home visits, based on much "farmer to farmer" communication techniques. This showed that the dissemination plan was not limited to a single method, but encompassed a variety of available methods and activities for this district. It also did not have a linear type of flow of information, as some of the activities were led by the researcher and extension officers, while others were led by the farmers themselves. This was possible as the mother-baby on-farm trials were situated at selected farmers own properties, usually near to their homestead (as described by Snapp et al., 2019). The idea was that the mother trial had all the treatments in a completely replicated statistical trial, but that each farmer with a "baby trial" only selects certain aspects for their four plots. These are not "demonstration plots" which are used in a top-down approach, but here the farmers were actually carrying out their own experiments under their own management style and environmental conditions. The motherbaby trials were developed during an intensive participatory engagement or focus group discussion. During that meeting, the Mujika farmers decided that the on-farm trials should address fertilizer, tillage practices and varieties. The treatments chosen to be tested were two maize varieties, two tillage practices and four fertility levels according to the forecast received (Nanja and Walker, 2010). Then each of the nominated farmers had only four plots to compare certain specific aspect, for example two varieties using two tillage methods. Thus, it was easy for them to show their visitors or fellow farmers the trials and explain the different treatments. This also provided an opportunity for the development of "transferable skills" amongst the farmers as part of the empowerment and capacity building effort. As they shared the detailed information about the on-farm trials, they were developing their confidence and communication skills. This proved to be a useful means of involving and stimulating the curiosity of the other farmers in the villages, as they became attentive in the trials and then would ask questions at the group meetings (Makuvaro et al., 2018). This was a good learning process for many of the farmers. Many of these activities provided opportunities and promoted discussion which resulted in lifelong learning about influence of climate on crop production.

The focus of these Agromet Advisories for the Mujika villages was on the use of the seasonal rainfall outlook regularly provided by the ZDM at the beginning of the rainfall season in spring or early summer. The researchers, together with the extension officers, then added pertinent farming information to the 3 month rainfall outlook. The type of information that was provided was for the maize crop as the main staple diet of that area. Some of the advisories included information for the planning of the planting of maize, such as which fields should receive priority according to the type of soil and amount of rain expected. Farmers then used that information to make their own decisions concerning their agronomic activities. These advisories included information about the selection of suitable varieties based on the relative amount of rainfall expected during the upcoming season, being formulated according to whether the rain would be above normal or near normal or below normal. Similarly, advice about application of fertilizer as basal preplant or top dressing was also given according to the expected rainfall. For example, if the rainfall outlook was for above normal rainfall, then they should not plant on the low lying areas near to the streams with heavy clay soils, but rather on the more gravelly soils on the slopes. Also they could plant longer growing season and later maturing varieties to make better use of the available rainfall and soil water, by applying good top dressing of fertilizers in the middle of the season. In contrast, for below normal rainfall seasons they could plant on the heavier soils with shorter maturing varieties and lower fertilizer applications. Therefore, these agromet advisories were addressing the high rainfall variability in this part of Zambia 
(Nanja, 2010) and enabled the farmers to build their resilience to this climate variability.

These valuable interactions between the researchers, farmers and extension personnel through the whole cropping cycle resulted in co-development of tailored Agromet advisories. One of the challenges was how to encourage farmers to attend small group or large community meetings where the seasonal climate forecast was delivered. One method used was to have farmers explain the forecast to their fellow farmers. Another challenge was to maintain the on-farm baby trials, as each season 16 farmers began, during the first season 14 completed but during the last season only half managed to complete and harvest them. As the particular focus was on improving the climate resilience of the cropping component of the local farming systems, it was important that the on-farm baby trials were managed by the specific farmers themselves. One valuable lesson learnt was that as key farmers and extension were included in all the activities from the beginning of the process, they were later enthusiastic and willing to drive the dissemination of the information themselves, in a farmer to farmer process. It also became apparent that with the support from the researcher and extension, farmers gained self-confidence and independence in making changes and using the available information in their decision making.

\section{SCIENCE FIELD SHOPS}

Science Field Shops (SFS) are groups of farmers and experts meeting regularly to exchange information about interactions between weather/climate and farming activities in Indonesia (Stigter and Winarto, 2013). Farmers, in rainfall observer groups, measure rainfall each day, together with other observations of their agro-ecological systems (see list of climate services later). At regular monthly meetings the seasonal forecasts are discussed in relation to rainfall received and the farmers anticipate conditions and options for the upcoming season. These are two of the climate services for the farmers included in SFS, others will be mentioned later. This agrometeorological learning is trans-disciplinary thorough interaction with the farmers by anthropologists from Universitas Indonesia-Department of Anthropology, agrometeorologist from the University of Free State, South Africa and extension practitioners from the Indonesian Ministry of Agriculture (Winarto et al., 2018). The transdisciplinary learning is the exploration of a range of relevant concepts, issues or problems by integrating the perspectives of multiple disciplines in order to connect new knowledge and deeper understanding to real life experiences. The anthropologists contributed with their broad approach to understanding the many different aspects of the human experience, by seeking cultural and historical evidence, understand change, comparing and contrasting information, so as to make connections and insights about farmer social existence. The agrometorologist contributed information about the interactions between climate/weather and farming systems, and insights into possible adaptations to improve sustainability. Extension practitioners are intermediaries between researchers and farmers, helping farmers to use appropriate knowledge in their decision making for sustainable production.

SFS principles include dialogue-discussion methods with engagement and exchange of knowledge between farmers and scientists (Vaarst et al., 2011; Mohtar and Daher, 2016). Farmers, scientists, extension officers and students enter into a conversation and discussion that has value and content around the interrelationships between farming and the climate. This is the place where the internal and external knowledge sets meet and the dialogue occurs which then helps the knowledge to be translated into the framework of the farmers' own world (Vaarst, 2011). Thus, "new knowledge" (as one of the SFS climate services) appropriate to their farming systems is generated, to serve the local farmers under their current conditions. These dialogues serve as a platform of mutual support for the farmers of each other while allowing for interpersonal responsiveness resulting in a clear understanding of the situation. Therefore, everyone benefited from such dialogues and the farmers were able to interact and discuss the options available and evaluate the consequences for their own farm (Vaarst et al., 2011). These focused discussions are the process of talking about the current situation and weather conditions in order to exchange ideas and to reach a decision about the best possible farming actions. Both scientists and farmers are continually learning and applying their knowledge using climate information to think out logical recommendations for evidence-based decisions for optimal agricultural productivity. Therefore, the foundation of SFS is good rapport between farmers and scientists with a common goal of exchanging information about seasonal rainfall forecasts to improve farming decisions.

As the SFS discussions are based on the local farming systems, they are really a place where the farmers acquire knowledge and agromet advisories in a face-to-face manner from each other and the scientists. SFS include eight basic climate services (Winarto et al., 2018), namely daily rainfall measurements; agroecological observations in their fields; analysis/evaluation of yields amongst farmers from different locations, across different seasons, and different years; monthly rainfall scenario outlook discussions; problem-solving by farmer experimentation in their fields to develop strategies to sustain yields; exchange of scientific "new" knowledge; organization of SFS groups and storage and digital analysis of farmers' rainfall data (Winarto et al., 2019, 2020). Each of these is vital to the understanding of the farming system and the interactions with the environment as well as the local climate and weather phenomena.

The farmers must commit to make their own rainfall measurement each day at the same time and keep a good record of these measurements. This enables then to relate the conditions and experience on their own farm to the area as a whole and also to the seasonal forecasts. It helps them to have a good basis from which to understand climate variability, as they can experience first-hand that each day or week or year is not the same. They have developed a better comprehension of the fluctuations and even the extremes experienced in the rainfall between seasons. Following the input from the agrometeorologist scientists during the farmer facilitator training sessions, they could also relate their own rainfall records to the worldwide climate indicators 
such as ENSO (El Niño-Southern Oscillation). This enables them to appreciate and comprehend the possibilities of what can occur in the upcoming season from the interaction of their own farming system with the global climate variability. So when they receive the monthly update about the current ENSO conditions, then they are able to discuss the options in their groups and make educated decisions about farm activities in the coming period. This process of anticipation of the future rainfall events and the knock-on effects on their farm as reported by Winarto et al. (2019), has been well-developed by the farmers themselves and shown many benefits being instrumental in improving their sustainability and productivity over the years since SFSs were organized in 2008.

The recording of the state of the agro-ecological conditions in their own fields, is also a learning process that had rewarded the farmers over the years. As they have documented the relationships between all the various aspects, they can consider these factors when planning for the following season. This feedback loop has proved to be a great learning process and provided the farmers with valuable insights into the cause and effect relationships on their own farms. For example, as they walked in the field every day, they observed the beginning of a pest breakout and were able to work proactively to prevent largescale damage to their crops, in contrast to other farmers who may not enter their fields on a daily basis. In future they will also be more diligent to check for certain pests and disease according to the weather conditions they have been observing. Therefore, this transdisciplinary learning from farmers to scientists in varied fields brings a holistic view to the agricultural production system and promotes sustainability and productivity (Mubaya et al., 2015).

SFS are based on using transdisciplinary research principles in practice with the farming community. The scientist team was composed of anthropologists, agrometeorologist and extension practitioners as well as other agricultural experts as and when they are needed to answer specific questions from the farmers. As the world is not segregated into compartments according to disciplines, so to the research and applications should also be across disciplines. The principle of transdisciplinary research is explained as a broad concept including many ways of working itself out in reality but all "transcends the narrow scope of disciplinary worldviews” (Klein, 2013).

The concept of SFS has some overlapping aspects with the FFS (Farmer Field Schools) and CFS (Climate Field Schools) in that they are engagements between scientists and the farmers (Van Den Berg and Jiggins, 2007; Friis-Hansen and Duveskog, 2012), and CFS address climate aspects of agriculture (Siregar and Crane, 2011). However, the advantage of the Science Field Shops is that they become an institution in and of themselves within the community, led by the community members themselves. So, unlike the FFS and CFS, where the training may take place over a few weeks or a growing season (Van Den Berg and Jiggins, 2007), the SFS provide a continuing lifelong learning opportunity for the farmers and they are self-governing groups like an NGO (non-governmental organization) or a CBO (community based organization). This lifelong learning as the continued ongoing, voluntary, and self-motivated pursuit of knowledge by the farmers is due to the fact that they can see the continued benefit of the rainfall measurements groups. Therefore, as well as enhancing social inclusion and active citizenship, there are benefits of personal development, and farming self-sustainability, as well as some factors of competitiveness and employability for those engaging in these activities. These aspects of the SFS are in contrast to a more top-down approach in FFS which can result in the disappearance of the control group of farmers who continue with their own traditional practices (Van Den Berg and Jiggins, 2007). However, this presents a challenge to upscaling SFS, as it required intensive engagements with each different group of farmers in each new region. For this to be successful buy-in and support from the government structures is needed. The SFS focus on the local agricultural systems and market opportunities to address the complex issues and priorities of farming communities, as it is a bottom-up capacity building lifelong learning approach through whereby farmers enhance their analytic and problem-solving abilities as recommended by Van Den Berg and Jiggins (2007).

A lessons learnt was that as the farmer observers gained self-confidence in understanding their own rainfall records relationship to the season forecasts, they were confident to speak to the village leaders and gain their respect as advisors. So, farmers are now making their own agromet advisories based on their own experience and information from international climate centers. Farmers use their rainfall observations (represented in simple hand-drawn diagrammes) together with the scientific interpretation of seasonal forecasts to develop tailor-made climate services related to local farming systems. This enables farmers to use climate information for improved management decisions both for themselves and for their neighbors or to give advice to the village leaders. This learning process has empowered farmers to address challenges on their own, and sustain and improve their productivity. Such co-development of agromet advisories is highly beneficial and locally based, however, the concept can be transferred to other areas and regions as the foundation is firmly on good communication and good science and respect across the transdisciplinary groups.

\section{AGRICLOUD}

AgriCloud is an online weather-based agricultural advisory system that enriches weather and climate forecasts with pertinent agricultural information and local agricultural knowledge. Real-time personalized overviews, forecasts, and warnings are generated and tailored to the particular farmer's needs. This is achievable because the users select and mark their own specific location on a google map at registration on the smart phone mobile App. Then users can receive the information for this precise location from the $15 \times 15 \mathrm{~km}$ grid used for the weather forecasts. AgriCloud provides farmers, extension staff and advisors in South Africa with daily updated weather-related farm specific advice. AgriCloud does not provide a weather forecast for the predicted rainfall and/or temperatures as on many weather Apps, but AgriCloud provides added value that it relevant to the dominant maize rainfed farming system. 
AgriCloud information is available via an android mobile App; an API tailor-made for a client to use via their own platform. During the R4A project, a USSD system was also developed for farmers without smart mobile phones. Alternatively a client or reseller can connect by subscription for tailor-made advisories, information and maps delivering selected information for their selected region. On the mobile AgriCloud App users obtain forecasts of planting dates for rain-fed crops in the next 10 days and suitable spray conditions, for herbicides and pesticides, according to time of day. All advisories are available in 11 South African official languages. Advisories were based on real-time weather observations and forecasts from ECMWF (European Center for Medium-Range Weather Forecasts) or GFS (Global Forecast System) numerical models and locally developed agricultural knowledge engines with crop specific algorithms. The AgriCloud App was developed during the "Rain4Africa" (R4A) project funded by the Netherlands Space Office together with Dutch partners. Data and advisories from South African Agricultural Research Council (ARC), South African Weather Services (SAWS) and ECMWF include ground based automatic weather station observations, radar and satellite integrated rainfall surfaces. The process followed for the development of the AgriCloud agromet advisory messages was an approach including engagements with the farming community and applied science developments.

The science and IT developments included expansion to the HydroNet platform (https://www.hydronet.co.za/) from its water-climate focus to include some aspects of climateagriculture interactions. HydroNet is used by the catchment management agencies as a web-based information and decision support system for water management. It combines weather, climate and water data and models with local knowledge to generate location specific information in the form of area overviews forecasts and warnings according to stakeholders needs. The water control room is used across South Africa by water resource managers and engineers at the Department of Water and Sanitation via specially formulated dashboards to generate hydrological reports. During the R4A project some of these aspects were expanded to include aspects important for agricultural water management as well.

Other scientific aspects included the development of algorithms or knowledge engines (Jahanshiri and Walker, 2015) specifically designed to address some of the critical aspects for optimal maize cultivation. As many losses in southern African maize production are weather related, it was important to include the weather forecast and then develop such relationships as explained by Myeni et al. (2019), Myeni and Moeletsi (2020). Aspects that are critical include the correct planting dates and control of pests and diseases. Therefore, algorithms, screening and trigger factors were developed to use the current weather parameters and their relationships with maize growth and development to generate agricultural advisories on a daily basis.

The principles of response farming (Stewart, 1988; Stigter et al., 2013) have been used in the development of the planting advisory for the rainfed maize in South Africa. This means that a certain amount of rainfall should be received within a stipulated time period before one can plant. This is based on the principle that water is needed around the seed to allow it to germinate, so following receiving this amount of rain it is deemed that sufficient moisture should be available in the top soil. In the AgriCloud app both the past observed and the rainfall expected from the medium-term weather forecast are used in this calculation (Walker, 2020). Then farmers can use this information to make plans for their planting activities by usually waiting for sufficient rainfall before planting the maize seeds (Moeletsi et al., 2013a; Makuvaro et al., 2014, 2017). The agromet advisory was presented in the AgriCloud App as a calendar block for the following 2 weeks with green shading to show that conditions are conducive for planting or a red shading to show that it would better not to plant on those days. This data is updated on a daily basis so can be available to the farmers for their own specific farm location when they open the app. An additional feature developed for AgriCloud was the crowd sourcing section. Here the user can give feedback to the app developers on the current extreme weather conditions. This is via a selection mode where one can select an icon that represents the current weather conditions and then earn some points for their contribution. At present the icons represent severe weather conditions, including hail, thunderstorms, frost, high winds, tornadoes, misty conditions, rain or floods. This provided a two-way communication channel on AgriCloud that can be further developed for other applications.

As a large part of the summer rainfall region in South Africa is in the Highveld on the South African inland plateau at altitudes above roughly $1500 \mathrm{~m}$ but below $2100 \mathrm{~m}$, frost is a regular winter occurrence. As maize is sensitive to temperatures below $10^{\circ} \mathrm{C}$, it must be planted where there is at least a 120 day frost free window (McMaster and Wilhelm, 1997). Therefore, a first screening of the long-term first and last frost dates was used to exclude planting dates within such time periods (Moeletsi et al., 2013b, Moeletsi and Walker, 2013). In this way certain dates for certain locations will be excluded from further calculations and will return a "do not plant" message to the farmers in those areas regardless of the amount of rainfall they have received, due to the danger of frost damage to the seedlings.

The farming community interactions during the R4A project included focus group discussions with training on the use of seasonal forecasts, and a survey through a pre-tested, structured questionnaire to assess farmers needs and understanding of climate change. The information collected highlighted the fact that many farmers in rural areas do not have smart phones and that the mobile network is poor in some locations. This hinders their use of such Apps. It also showed that most small-scale farmers only access the weather forecast via the TV or radio broadcasts, and that is only available for the main centers. So they need more detailed information for their own specific locality as they know that there are differences from the nearest city. Therefore, it was again highlighted that farmers need routinely updated weather information for their own areas that they could use when planning their farm activities. Therefore, it was vital to develop agromet advisories for specific farming systems in specific areas and to be able to deliver them on a routine basis.

Following the formulation of the agromet advisories, a series of meetings were held with the personnel from the departments of agriculture in selected provinces as a way of 
testing the AgriCloud app with the users (with more than 540 attendees). These meeting were held between May and October 2018 and the comments received were integrated into a revised AgriCloud App. Further engagements were via the extension officers from October 2018 continuing into 2019, when a number of information training type meetings were held, with more than 1,000 extension officers attending across 6 provinces. These trainings sessions were held during the rollout of the AgriCloud mobile app at the beginning of the 2018 rainy season in South Africa. It is estimated that these extension officers serve about 400,000 small-scale farmers. Some of the comments received from them include the following stumbling blocks encountered, such as poor access to mobile network or little data and not understanding the functions on the smart phones. Many extension officers also requested other functions on the AgriCloud App, particularly pertaining to livestock and vegetable production activities. However, by the end of the R4A project more than 1,500 people had downloaded the AgriCloud App from Google play store and about $70 \%$ of users were also returning on a regular basis. This illustrates that the agromet advisory information is being used as it has some unique aspects, namely that it is available in the 11 South African official languages, it is giving the information for one's own farm on one's own mobile smart phone with daily updated information for the upcoming 10-14 days.

Some of the lessons learnt during the R4A project, include the need for continued openness to listen to the clients, extension and farmers in this case, while maintaining regular communication and building credibility for the usefulness of the products. One of the big challenges was to try to evaluate the effect the increased availability of agromet information on the dryland cropping systems. As variation in yields is so large between years and dependent on the rainfall amount and distribution through the season, it was not possible to only compare production between years. This needs to be approached in a different manner in future, possibly by using crop modeling and historic weather datasets. But that would not include the essential element of the farmers decision making processes.

\section{CONCLUSIONS}

These three examples from three different countries, show how the scientific weather forecasts can be used together with especially co-developed tailored agricultural forecasts to inform farmers and supply them with updated information on a daily basis. Scientists from different disciplines were involved in all three examples, showing the importance of transdisciplinary teams and how they complement each other by bringing different skills to the team. This is especially apparent in SFS where anthropologists were the initiator and team leaders, as during their exchanges with the farmers, they realized the need for expertise about climate change and adaptations. The anthropologists gained a deeper understanding of the interactions between weather/climate and crop production under a changing climate. The natural scientists learnt good social skills for interacting with farming communities during these co-development activities and the farmers benefited from the participatory team effort. Good communication systems are vital to deliver and receive feedback on Agromet advisories. The three examples highlighted different modes of stakeholder engagement and routine delivery of the agromet advisories. All used some form of focus group discussions, with close inperson interactions between the researchers and the farmers. This enabled the incorporation of local knowledge into the codevelopment of pertinent advisories suitable for the farmers and their own farming systems and situation. In SFS and CAPES farmers formed their own groups that met regularly to discuss the climate information and how it affected their farm level options and decisions. So these study groups became the made mode of regular information dissemination, as it allows immediate feedback and detailed discussions about the topics that arise. As AgriCloud is a mobile app, it does not offer such an opportunity, however, the crowd sourcing function is a step toward receiving feedback from the farmers. In future various combinations of these methods can be used to develop locally useful agromet advisories for other farmers and farming systems under a variety of climatic conditions around the world. It is vital that good weather forecasts are available and a co-development process with farmers uses local information about the agricultural systems to integrate into an acceptable and appropriate communication system. Such systems can then be used on a routine basis to reach as many farmers and farm managers provided that there are opportunities for two-way communication and continued refinement and co-developed of the agromet advisories with the farmer users.

\section{DATA AVAILABILITY STATEMENT}

The original contributions presented in the study are included in the article/supplementary material, further inquiries can be directed to the corresponding author.

\section{AUTHOR CONTRIBUTIONS}

The author confirms being the sole contributor of this work and has approved it for publication.

\section{FUNDING}

The following organizations were thanked for continued funding support over many years-University of the Free State, South African Agricultural Research Council, South African National Research Foundation, South African Water Research Commission, Universatas Indonesia, and for specific project funding from Canadian International Development Research Center (IDRC), Netherlands Space Office, G4AW (Geodata for Agriculture and Water), Indonesia Climate Change Trust Fund of the Ministry for Planning and Development and KONSEPSI Consortium for Study and Development Participations. 


\section{ACKNOWLEDGMENTS}

The author thanks the Rain4Africa team members and organizations namely SAWS, HydroLogic and Weather Impact who made major contributions to development

\section{REFERENCES}

Ager, A., Stark, L., and Potts, A. (2010). Participative Ranking Methodology: A Brief Guide. New York, NY: Columbia University, 18.

Carberry, P. S., Hochman, Z., McCown, R. L., Dalgliesh, N. P., Foale, M. A., Poulton, P. L., et al. (2002). The FARMSCAPE approach to decision support: farmers', advisers', researchers' monitoring, simulation, communication, and performance evaluation. Agr. Syst. 74, 141-177. doi: 10.1016/S0308-521X(02)00025-2

Chambers, R. (2006). Participatory mapping and geographic information systems: whose map? who is empowered and who is disempowered? who gains and who loses. Electron. J. Inform. Syst. Dev. Countries 25, 1-11. doi: 10.1002/j.1681-4835.2006.tb00163.x

Chambers, R. (2007). From PRA to PLA and Pluralism: Practice and Theory. IDS Working Paper, no. 286. Brighton: Institute of Development Studies, 41.

Eldon, J., Baird, G., Sidibeh, S., Dobasin, D., Rapaport, P., Cheng, W., et al. (2020). On-farm trials identify adaptive management options for rainfed agriculture in West Africa. Agr. Syst. 182:102819. doi: 10.1016/j.agsy.2020.102819

Elhag, M. M., and Walker, S. (2011). A decision support tool to assess desertification condition in arid and semi-arid regions. Int. J. Water Resour. Arid Environ. 1, 378-381. Available online at: http://www.integral-review.org/ issues/vol_9_no_2_klein_the_transdiciplinary_moment(um).pdf

Friis-Hansen, E., and Duveskog, D. (2012). The empowerment route to well-being: an analysis of farmer field schools in East Africa. World Dev. 40, 414-427. doi: 10.1016/j.worlddev.2011.05.005

Gandure, S., Walker, S., and Botha, J. J. (2013). Farmers' perceptions of adaptation to climate change and water stress in a South African rural community. Environ. Dev. 5, 39-53. doi: 10.1016/j.envdev.2012.11.004

Hall, R., Brent, Z., Franco, J., Isaacs, M., and Shegro, T. (2017). A Toolkit for Participatory Action Research. Ottawa, ON: International Development Research Centre (IDRC), 16. Available online at: http://hdl.handle.net/10566/ 4112 (accessed May 11, 2021).

IFAD (2009). Good Practices in Participatory Mapping. Rome: International Fund for Agricultural Development, 59.

Jagtap, S. S., Jones, J. W., Hildebrand, P., Letson, D., O’Brien, J. J., Podest,à, G., et al. (2002). Responding to stakeholder's demands for climate information: from research to applications in Florida. Agr. Syst. 74, 415-430. doi: 10.1016/S0308-521X(02)00048-3

Jahanshiri, E., and Walker, S. (2015). Agricultural knowledge-based systems at the age of semantic technologies. Int. J. Knowl. Eng. 1, 64-67. doi: 10.7763/IJKE.2015.V1.11

Jones, A., Breuning-Madsen, H., Brossard, M., Dampha, A., Deckers, J., Dewitte, O., et al. (eds.). (2013). Soil Atlas of Africa. Luxenbourg: European Commission, Publ. Office European Union, 176.

Klein, J. T. (2013). The transdisciplinary moment(um). Integ. Rev. 9, 189-199.

Makuvaro, V., Walker, S., Munodawafa, A., Chagonda, I., Masere, P., Murew, C., et al. (2017). Constraints to crop production and adaptation strategies of smallholder farmers in semi-arid central and western Zimbabwe. Afr. Crop Sci. J. 25, 221-235. doi: 10.4314/acsj.v25i2.7

Makuvaro, V., Walker, S., Munodawafa, A., Masere, T. P., Murewi, C., et al. (2014). An overview of current agronomic practices of smallholder farmers in semi-arid Central and Western Zimbabwe. Afr. J. Agric. Res. 9, 2710-2720. doi: 10.5897/AJAR11.606

Makuvaro, V., Walker, S., Masere, T. P., and Dimes, D. (2018). Smallholder farmer perceived effects of climate change on agricultural productivity and adaptation strategies. J. Arid Environ. 152, 75-82. doi: 10.1016/j.jaridenv.2018.01.016

McMaster, G. S., and Wilhelm, W. W. (1997). Growing degree-days: one equation, two interpretations. Agric. For. Meteorol. 87, 291-300. doi: 10.1016/S0168-1923(97)00027-0 of AgriCloud. The Science Field Shops work was carried out together with Yunita Winarto and Rhino Ariefiansyah, from the Universatas Indonesia. CAPES was developed during Durton H. Nanja Ph.D. study in Zambia.

Moeletsi, M. E., Mellaart, E. A. R., Mpandeli, N. S., and Hamandawana, H. (2013a). The use of rainfall forecasts as a decision guide for small-scale farming in Limpopo Province, South Africa. J. Agric. Educ. Exten. 19, 133-145. doi: 10.1080/1389224X.2012.734253

Moeletsi, M. E., Moopisa, S. G., Walker, S., and Tsubo, M. (2013b). Development of an agroclimatological risk tool for dryland maize production in the Free State Province of South Africa. Comput. Electron. Agric. 95, 108-121. doi: 10.1016/j.compag.2013.04.006

Moeletsi, M. E., and Walker, S. (2013). Agroclimatological suitability mapping for dryland maize production in Lesotho. Theor. Appl. Climat. 114, 227-236. doi: 10.1007/s00704-012-0829-1

Mohtar, R. H., and Daher, B. (2016). Water-Energy-Food Nexus framework for facilitating multi-stakeholder dialogue. Water Int. 41, 655-661. doi: 10.1080/02508060.2016.1149759

Mubaya, C. P., Mugabe, F. T., and Walker, S. (2015). "Carving a niche for the social sciences in transdisciplinary research on climate change adaptation in Southern African agriculture," in Global Sustainability Cultural Perspectives and Challenges for Transdisciplinary Integrated Research, Part II Knowledge Production and Action, ed B. Werlen (Berlin: Springer), 107-117.

Myeni, L., Moeletsi, M., Thavhana, M., Randela, M., and Mokoena, L. (2019). Barriers affecting sustainable agricultural productivity of smallholder farmers in the eastern Free State of South Africa. Sustainability 11:3003. doi: $10.3390 /$ su11113003

Myeni, L., and Moeletsi, M. E. (2020). Factors determining the adoption of strategies used by smallholder farmers to cope with climate variability in the Eastern Free State, South Africa. Agriculture 10:410. doi: 10.3390/agriculture10090410

Nanja, D. H. (2010). Dissemination of climate information to small-holder farmers: A case study for Mujika area, Zambia (Ph.D. in Agrometeorology). University of Free State, Bloemfontein, South Africa.

Nanja, D. H., and Walker, S. (2009). Handbook for Community Agrometeorological Participatory Extension Service (CAPES). Bloemfontein: University of the Free State and Monze. Available online at: http://www.agrometeorology.org/filesfolder/repository/HandbookCAPES.pdf (accessed May 11, 2021).

Nanja, D. H., and Walker, S. (2010). "Changes in farmer decision making under a variable Monze climate," in Climate Change in Africa: Research Insights on Adaptation at Local and Regional/Sub-Regional Scales at the ACCFP Round I Culmination Conference, 8-10 December 2010 (Dakar).

Nyumba, T. O., Wilson, K., Derrick, C. J., and Mukherjee, N. (2018). The use of focus group discussion methodology: insights from two decades of application in conservation. Meth. Ecol. Evol. 9, 20-32. doi: 10.1111/2041-210X. 12860

Périnelle, A., Meynard, J.-M., and Scopel, E. (2021). Combining on-farm innovation tracking and participatory prototyping trials to develop legume-based cropping systems in West Africa. Agr. Syst. 187:102978. doi: 10.1016/j.agsy.2020.102978

Siregar, P. R., and Crane, T. A. (2011). Climate information and agricultural practice in adaptation to climate variability: the case of Climate Field Schools in Indramayu, Indonesia. Cult. Agric. Food Environ. 33, 55-69. doi: 10.1111/j.2153-9561.2011.01050.x

Snapp, S. S., DeDecker, J., and Davis, A. S. (2019). Farmer participatory research advances sustainable agriculture: lessons from Michigan and Malawi. Agron. J. 111, 1-11. doi: 10.2134/agronj2018.12.0769

Stewart, J. I. (1988). Response Farming in Rainfed Agriculture. Davis, CA: The WHARF Foundation Press, 103.

Stigter, C. J., and Winarto, Y. T. (2013). Science Field Shops in Indonesia: a start of improved agricultural extension that fits a rural response to climate change. J. Agric. Sci. Appl. 2, 112-123. doi: 10.14511/jasa.2013.02 0210 
Stigter, K., Walker, S., and Das, H. (2014c). Meeting farmers' needs for agrometeorological services: a review with case studies Part III: Context 2, the future. Ital. J. Agrometeorol. 2104, 45-52. Available online at: https://riviste. fupress.net/index.php/IJAm/issue/archive

Stigter, K., Walker, S., Das, H., Dominguez-Hurtado, I. M., and Nanja, D. (2014a). Meeting farmers' needs for agrometeorological services: a review with case studies Part I: Introduction and history. Ital. J. Agrometeorol. 1/2014, 59-65.

Stigter, K., Walker, S., Das, H., Huda, S., and Haasbroek, P. D. (2014b). Meeting farmers' needs for agrometeorological services: a review with case studies Part II: Context 1, the existing situation. Ital. J. Agrometeorol. 2/2014, 51-60.

Stigter, K., Winarto, Y. T., Ofori, E., Zuma-Netshiukhwi, G., Nanja, D., and Walker, S. (2013). Extension agrometeorology as the answer to stakeholder realities: response farming and the consequences of climate change. Atmosphere 4, 237-253. doi: 10.3390/atmos4030237

Vaarst, M. (2011). "Dialogue towards animal health and welfare planning," in The Process of Minimising Medicine Use through Dialogue based Animal Health and Welfare Planning, eds M. Vaarst and S. Roderick, (Tjele: International Centre for Research in Organic Food Systems (ICROFS)). 38-43.

Vaarst, M., Roderick, S., Smolders, G., Leeb, C., Walkenhorst, M., Winckler, C., et al. (2011). "The dialogue with farmers," in The Process of Minimising Medicine Use through Dialogue based Animal Health and Welfare Planning, eds M. Vaarst and S. Roderick, (Tjele: International Centre for Research in Organic Food Systems (ICROFS)) 64-79.

Van Den Berg, H., and Jiggins, J. (2007). Investing in farmers-the impacts of Farmer Field Schools in relation to integrated pest management. World Dev. 35, 663-686. doi: 10.1016/j.worlddev.2006.05.004

Walker, S. (2020). Value-added weather advisories for small-scale farmers in South Africa delivered via mobile apps. Irrig. Drain. 70, 505-511. doi: 10.1002/ird.2506

Walker, S., Ofori, E., Kyei-Baffour, N., and Stigter, K. (2010). "Problems and solutions in using and coping with weather phenomena in need of tactical decision making and challenges remaining for the use of science to contribute to problem analyses and designing viable solutions in this context: multiple cropping," in Applied Agrometeorology, ed K. Stigter (Heidelberg: Springer), 493-498.

Walker, S., and Stigter, K. (2010). "Designing and selecting early warning strategies and increasing their efficiencies: multiple cropping," in Applied Agrometeorology, ed K. Stigter (Heidelberg: Springer), 485-492.
Winarto, Y. T., Walker, S., and Ariefiansyah, R. (2019). People, clouds and roots: between the unseen, the seen, and the unforeseen. Nat. Cult. 14, 236-250. doi: $10.3167 /$ nc.2019.140302

Winarto, Y. T., Walker, S., Ariefiansyah, R., Lisan, I. H., Bestari, M. Y., and Audina, T. (2020). "University's inclusion in providing climate services to farmers: Is it possible without agricultural agents and farmer facilitators?" in Climate Change, Hazards and Adaptation Options: Handling the Impacts of a Changing Climate, eds W. L. Filho, G. J. Nagy, M. Borga, P. D. Chávez Muñoz, and A. Magnuszewski (Berlin, Climate Change Management Series, Springer), 835-852.

Winarto, Y. T., Walker, S., Ariefiansyah, R., Prihandiani, A. F., Taqiuddin, M., and Nugroho, Z. C. (2018). Institutionalizing Science Field Shops: Developing Response Farming to Climate Change. Rome: Global Alliance for Climate Smart Agriculture. Available online at: http://www.fao.org/3/18454EN/i8454en. pdf (accessed May 11, 2021).

Zuma-Netshiukhwi, G., Stigter, K., and Walker, S. (2013). Use of traditional weather/climate knowledge by farmers in the South-Western Free State of South Africa: agrometeorological learning by scientists. Atmosphere 4, 383-410. doi: $10.3390 /$ atmos 4040383

Conflict of Interest: The author declares that the research was conducted in the absence of any commercial or financial relationships that could be construed as a potential conflict of interest.

Publisher's Note: All claims expressed in this article are solely those of the authors and do not necessarily represent those of their affiliated organizations, or those of the publisher, the editors and the reviewers. Any product that may be evaluated in this article, or claim that may be made by its manufacturer, is not guaranteed or endorsed by the publisher.

Copyright $(0) 2021$ Walker. This is an open-access article distributed under the terms of the Creative Commons Attribution License (CC BY). The use, distribution or reproduction in other forums is permitted, provided the original author $(s)$ and the copyright owner(s) are credited and that the original publication in this journal is cited, in accordance with accepted academic practice. No use, distribution or reproduction is permitted which does not comply with these terms. 